\title{
QUANTIFICATING THE OPHTHALMIC IRRITATION TEST OF PROTIC IONIC LIQUIDS USING IMAGEJ AND PHOTOSKAPE
}

\author{
Rebecca da Silva Andrade ${ }^{a}$, Gabriela Brasil Romão Veloso ${ }^{b}$, Bruna Galdorfini Chiari- \\ Andreo ${ }^{c}$, Miguel Angel Iglesias Duro ${ }^{b}$ \\ a Universidade Federal do Recôncavo da Bahia, Av. Centenário, 697, Sim, CEP \\ 44042-280 Feira de Santana, BA, Brazil. \\ ${ }^{b}$ Universidade Federal da Bahia, Rua Aristides Novis, 2, Federação, CEP 40210-630 \\ Salvador, BA, Brazil \\ ${ }^{c}$ Universidade de Araraquara - UNIARA, R. Carlos Gomes, 1217, CEP 14801-340 \\ Araraquara, SP, Brazil
}

\begin{abstract}
The HET-CAM (Hen's Egg Chorioallantoic Membrane) assay is a qualitative alternative method to the in vivo Draize Rabbit Eye test to assess the irritancy potential of chemicals. In this work, for the first time the ophthalmic irritation of 13 different protic ionic liquids has been evaluated using ImageJ and PhotoSkape image processing programs to analyze the results of the HET-CAM assay. The irritation potential of a substance can be quantified using these computational tools by observing blood vessel changes like lysis, hemorrhage and coagulation. In conclusion, the modification of the established HET-CAM assay made it possible to determine the damage to minute blood vessels, highlighting the low-irritant profile of some studied protic ionic liquids to the ocular tissues.
\end{abstract}

Keywords: Protic ionic liquids; ocular irritation, ImageJ, HET-CAM test.

\section{QUANTIFICAÇÃO DO TESTE DE IRRITAÇÃO OFTÁLMICA DE LÍQUIDOS IÔNICOS PRÓTICOS USANDO IMAGEJ E PHOTOSKAPE}

Resumo:O ensaio HET-CAM (Membrana Corioalantóica do Ovo de Galinha) é um método alternativo qualitativo para o teste in vivo de Draize para avaliar o potencial de irritação de produtos químicos. Neste trabalho, pela primeira vez, a irritação oftálmica de 13 líquidos iônicos próticos (LIPs) diferentes foi avaliada usando os programas de processamento de imagem ImageJ e PhotoSkape para analisar os resultados do ensaio HET-CAM. O potencial de irritação de uma substância pode ser quantificado usando essas ferramentas computacionais, observando as alterações dos vasos sanguíneos, como lise, hemorragia e coagulação. Em conclusão, a modificação deste ensaio tornou possível determinar o dano aos vasos sanguíneos diminutos, destacando o perfil de baixa irritação dos LIPs para os tecidos oculares.

Palavras-chave: Líquidos iônicos próticos; irritação ocular, ImageJ, teste HET-CAM. 


\section{INTRODUCTION}

lonic liquids (ILs) are innovative chemical compounds, which due to their specific physico-chemical behavior, have been studied as alternative sustainable solvents in many areas of modern science, as in the industrial fields of pharmaceutical, biotechnology, food and bio-products, textile processing and many others [1-4]. Due to their probable large-scale use in a next future, a wider analysis in terms of human and environmental safety has been attracting significant attention in the last few years. Precociously reported as "safe materials" due to their non-volatility and high thermal stability, many ionic liquids were found to be resistant to biodegradation and photo-degradation and toxic towards cells and living organisms [5-7].Despite the technical advantages of these compounds, these safety potential risks make necessary to find better alternative solvents with human-friendlier character. Once these ionic liquids can be modified or tailored by specific variations into the ionic structure, a new family of these molten salts has been proposed avoiding complex functional groups hardly biodegradable and potential hazardous molecular groups (halogens, heterocycles, etc). This new family, namely protic ionic liquids (PILs) is being increasingly studied and characterized by their physicochemical properties, and recent scientific research suggest its strong environmental friendly profile and its safety to specific kinds of human cells, as HaCat, HepG2, HEK (normal human embryonic kidney cells), Hs68 (fibroblast cell line),EA.hy926 (human umbilical immortalized cells) [8-11].

Part of this bio-safety analyze process is to elucidate the ophthalmic irritation potential of these new materials. In the regulatory context the term 'eye irritation' is generally defined as the development of undesirable changes in the eye after the application of a test substance to the anterior surface of the eye, which are reversible within twenty-one days of treatment. Regarding the ocular toxicity assessment, in vivo eye toxicity evaluation used to be performed based on the Draize test, where damage in cornea, conjunctiva, and iris of a rabbit is scored and used to classify the eye irritation/corrosion potential of achemical. But, it worth to mention that this test was not submitted to an official validation process and has shown incapability to predict eye toxicity potential of chemicals to humans.

Regulatory agencies as European Chemicals Agency (ECHA) in the European Union,Environmental Protection Agency(EPA) in United States and the United Nations Globally Harmonized System (GHS) of Classification and Labelling of Chemicals have published recently advices on using new or revised OECD test guidelines related to serious eye damage/eye irritation and skin corrosion/irritation, recommendingnon-animal testing as a default approach to gather such information [12-14]. In Brazil, until 2019, to evaluate these toxicological endpoints, most research used exclusively in vivo methods, which were accepted/recommended by the Brazilian Health Surveillance Agency (Agência Nacional de Vigilância Sanitaria, ANVISA). However, recently the brazilian legislation was updated and the new ANVISA norm includes acceptance of animal testing alternatives recognized by the OECD and adoption of the GHS criteria for eye toxicities categorizations, and the deadline for adoption of this new methodologies is 2021.

One alternative for the commonly applied in vivo Draize rabbit eye assay is the hen's egg test using the chorioallantoic membrane (HET-CAM test), developed by Luepke (1985), a cheap and successful test that has shown good correlation to 
ophthalmic irritation in the vivo situation. The HET-CAM test sits between in vivo and in vitro techniques, using fertile white leghorn chicken eggs instead of rabbits. The hen's egg chorioallantoic membrane (CAM) separates the embryo from the internal space and is a immunodeficient tissue containing arteries, veins and capillaries, which responds to injury with an inflammatory process similar to what one would observe in the conjunctival tissue of a rabbit's eye. Its well-developed vascularization provides an ideal model for ocular irritation studies.

In this work, as a continuation of a sequential testing strategy (Figure 1), these PILs were evaluated using the HET-CAM method, which allowed it classification based on eye vascular alterations. The outcomes of this study could provide rationale for the usefulness of the PILs in industrial applications in which there may be direct or indirect interaction of these compounds with humans.

Figure 1. Sequential testing analysis used in the bio-safety study of protic ionic liquids. Source: The authors themselves.

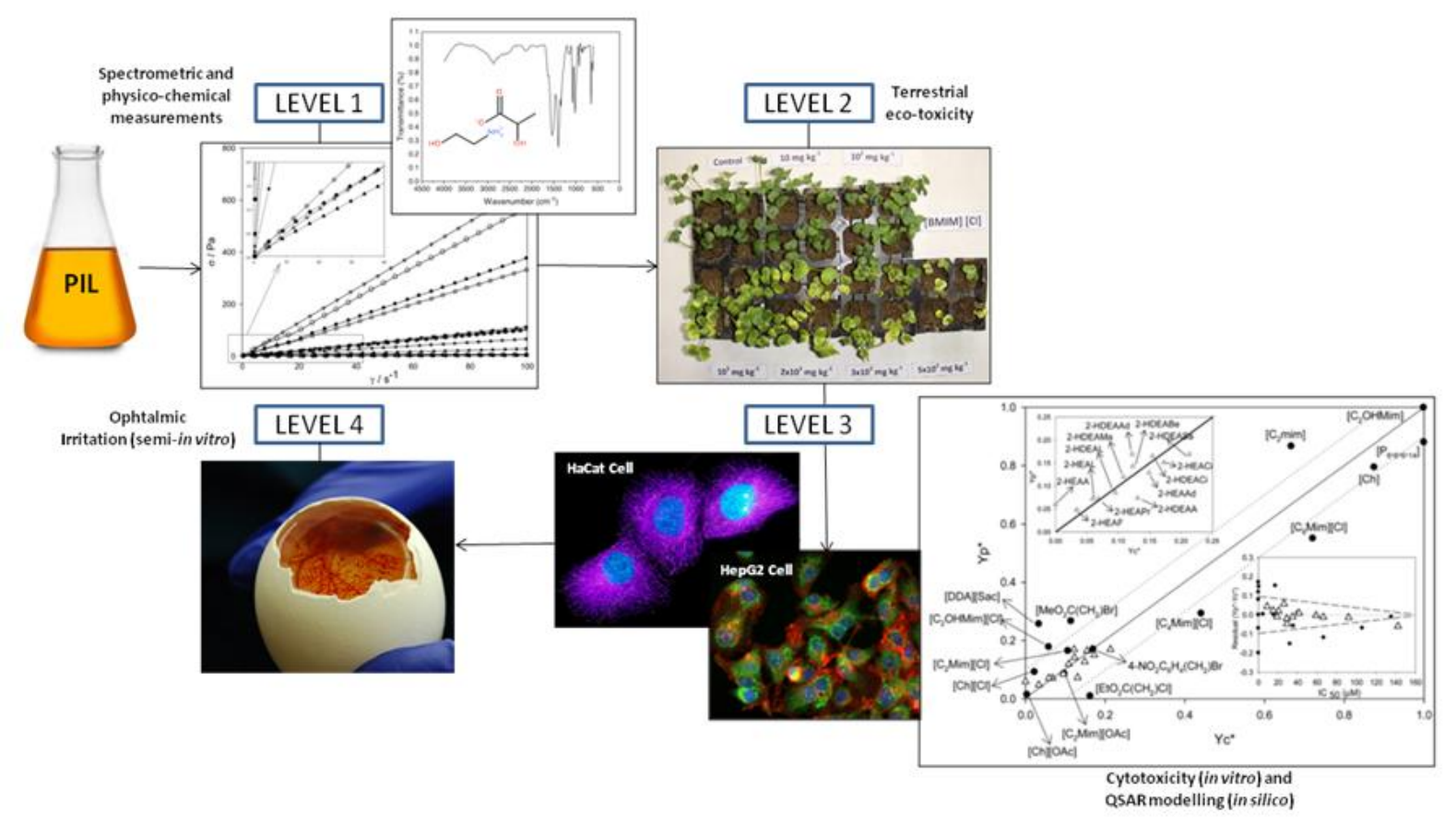

\section{METHODOLOGY}

For each PIL tested, four fresh fertile Leghorn eggs were used. The eggs were incubated at $37 \pm 0.5^{\circ} \mathrm{C}$ with a relative humidity of $60 \pm 2 \%$ for 10 days in the vertical position to ensure the correct positioning of the embryo (away from the chorioallantoic membrane). They were manually rotated $180^{\circ}$ two times a day for the duration of the test, to ensure correct development and viability of the embryo. On the tenth day, the eggs were removed individually from the incubator, and placed in a holder with the larger end upwards. The shell and the inner membrane were carefully scratched off with a cutter and then pared off with a fine forceps, exposing the chorioallantoic membrane. After verify visually if the CAM was suitable to test, $0.2 \mathrm{~mL}$ of each PIL was placed on the membrane surface. The same volume of sodium hydroxide $1 \mathrm{M}$ and phosphate buffered saline (PBS, $\mathrm{pH}=7.2$ ) solution was also added directly onto the CAM to serve as positive and negative controls, respectively. 
Any lysis, haemorrhaging and/or coagulationwas observed and photographs were taken at different times $(0 \mathrm{~s}, 30 \mathrm{~s}, 120 \mathrm{~s}$ and $300 \mathrm{~s}$ ) to record qualitative data. The photographs were examined using Photoscape and ImageJ softwares(available as freeware from http://rsb.info.nih.gov/ij/) to quantify the vascular damage, allowing a more detailed and robust analysis of the PILs to be made.

The images of the chorioallantoic membranes were loaded onto Photoscape and converted to greyscale. To quantify the extent of any hemorrhaging, hyperemia and coagulation, the files formed using Photoscape were loaded into ImageJ. To analyze the greyscale values of the pixels over a standardized length of membrane, a $25 \mathrm{in}^{2}$ square was carefully selected in an appropriate area to exclude the shell and any out of focus regions. The profile of the average grey pixel value along the rectangular area was plotted by pressing 'Analyze > Plot Profile'. Once the square has been adjusted to the standardized length, the menu option 'List' was selected and the values plotted using Sigmaplot.

\section{RESULTS AND DISCUSSION}

Taking into account the subjectivity of this assay, and the high probability of the observer not perceiving mild changes in blood vessels, and in order to quantify the photographic results, the images were subjected to software analysis using PhotoScape and Image (Figure 2), as recently proposed by Mackenzie et al [15]. The data was analyzed and processed as 'grey values', where lower values ('moreblack') correlates to hemorrhage or hyperemia and higher values ('more white') correlates to coagulation.

Figure 2. An example profile plot on ImageJ, highlighting the correlation between dark blood vessels and grayscale values. Source: The authors themselves.

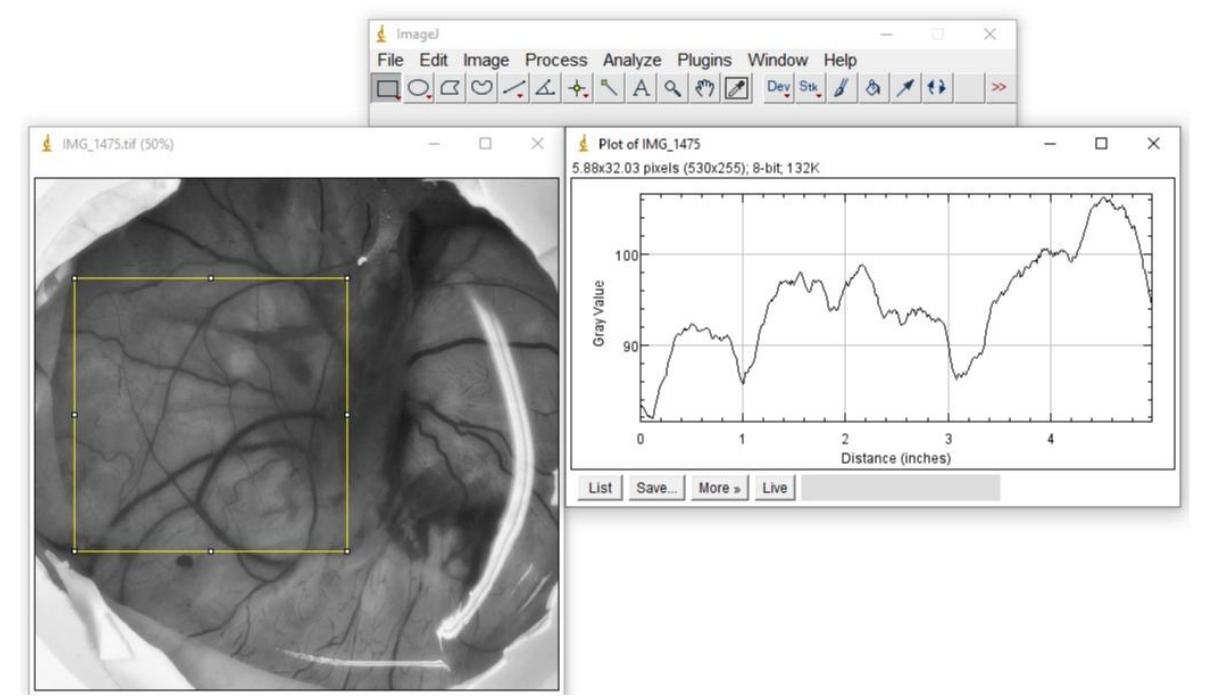

Since each egg has its own blood vessel network, the authors consider it inconsistent to use this quantification method to compare different samples; however, gray values of photographs taken over time for each sample tested were analyzed, which allowed a more objective assessment of the physiological response as a function of the time of the chorioallantoic membrane when in contact with each PIL individually. 
As observed, application of $0.2 \mathrm{ml}$ of phosphate buffered saline (PBS) solution to the healthy membrane produced no visual response over the $5 \mathrm{~min}$ period. On the other hand, the same volume of sodium hydroxide $1 \mathrm{M}$ produced a severe hemorrhage since the first moment. Over five minutes its injurious capability has progressively increased, grading this solution as a severe irritant to the ocular tissues.

According to the visual analysis, 2-HEACi and 2-HDEACi produced no relevant damage to the $\mathrm{CAM}$, with a behavior similar to the negative control, resulting in a cumulative score 1 and 0 , which classifies them as slightly-irritating and nonirritating PILs, respectively. As expected, it is possible to notice that the grey values for times $0,30,120$ and 300s approximately overlap for $2-\mathrm{HDEACi}$, indicating absence of physiological response, and slightly decreases for $2-\mathrm{HEACi}$, indicating a mild hyperemia, as observed visually. In both cases is possible to percept a slight coagulation at 30 s in a specific area (visually imperceptible, but clearly shown into the grey values graph), which, as observed, falls apart over time. Changes in blood vessels usually start quickly after injury or infection, but develop at varying speeds, depending on the nature and severity of the original inflammatory stimulus. It is common that before vasodilatation of the arterioles, resulting in increased blood flow and opening of the capillary beds (hyperemia), a slight transient vasoconstriction occurs as the first physiological response to the aggression.

Similarly, 2-HDEAL was graded as slightly-irritant according to Gupta method, presenting a cumulative score 3 due to a hyperemia detected between 30 and $120 \mathrm{~s}$ after the CAM's contact with the sample. As observed for other PILs, a slight constriction/coagulation, not visually perceived, is observed in the first $30 \mathrm{~s}$ of the test by the increase in the gray scale values, followed by an expected progressive hyperemia (decreasing grey values). 2-HEAL presented hyperemia in the first 30 seconds of the test, with no further associated effects, which theoretically graded it as a moderately-irritating liquid (cumulative score 5). However, after a slight initial reduction in gray values (darkening of the image, indicative of hyperemia), blood vessels tend to return to their original appearance, as evidenced by the superposition trend of the 0 s, 120 s and 300 s time curves.

Most of the studied PILs were categorized as moderately-irritating. With a cumulative score 5 due to a progressive slightly hyperemia since the first $30 \mathrm{~s}$ from the beginning of the test, without other associated effects, 2-HEAPr showed a moderately-irritant behavior equivalent to 2-HEAL, which was expected, since its structures are very similar and differ only by the presence of a hydroxyl group into the lactate compound.

2-HEAA and 2-HDEAA had cumulative scores 8 and 6 , respectively, due to the hemorrhagic response between times 120 and 300s for both, associated with a hyperemia effect observed in the first seconds of testing for 2-HEAA, and between 30 and 120 s for 2-HDEAA.It is important to note that the sample dripped on the chorioallantoic membrane often flows in preferential ways, revealing a physiological response concentrated in a reduced area of contact, which hinders the visual perception of the changes. This fact is observed in the gray scale graphs - in both cases, there is a tendency for the curves to overlap (indicative of no response to the stimulus), except at the bottom of the images, where it is noticeable the reduction of values since the time 30 s for the 2 -HEAA, and after the time 120 s for the 2 -HDEAA. 
2-HDEABe and 2-HDEASa, the only studied aromatic PILs, showed cumulative scores 7 and 5 , respectively, due to a hemorrhage observed in the first 30 $\mathrm{s}$ for the benzoate salt and between $30 \mathrm{~s}$ and $120 \mathrm{~s}$ for the salicylate salt. In both cases, no associated effects were visually observed. Clearly is possible to see the reduction over time of the gray values for the 2-HDEABe, indicating that the bleeding started in 30 s is not contained, but shows a progressive increase with time.

2-HEAAd and 2-HDEAAd showed cumulative scores 8 and 7, respectively. The contact of the CAM with 2-HEAAd resulted in a slight hyperemia in the first contact (before 30s), followed by a hemorrhage observed from the 300s of test. On the other hand, 2-HDEAAd allowed visual perception of a hemorrhagic effect at the first moment without any other associated effect.

2-HEAF and 2-HDEAMa were the only two studied PILs that had a severelyirritating profile. With a cumulative score 10 , the contact of both with the chorioallantoic membrane resulted in hyperemia in the first $30 \mathrm{~s}$, followed by hemorrhage observed between 30s and 120s. Figures 7C and SG show a progressive decreasing trend in gray values, an indicative result of progressive hyperemia/hemorrhage over time.

In general terms, it is important to highlight that, for the same anion, the diethanolamine salts showed less irritating potential than the respective monoethanolamine salts (2-HEAA>2-HDEAA, 2-HEAL>2-HDEAL, 2-HEAAd>2HDEAAd and 2-HEACi>2-HDEACi). Triethanolamine (TEA), Diethanolamine (DEA), and Monoethanolamine (MEA) are amino alcohols used in cosmetic formulations as emulsifiers, thickeners, wetting agents, detergents, and alkalizing agents, and have been studied regarding its eye irritation potential in rabbits and rhesus monkeys. In high concentrations and with long contact time, TEA, DEA, and MEA are irritating to the rabbit eye at concentrations of $100 \%, 50 \%$, and $5 \% \mathrm{~m} / \mathrm{m}$, respectively, i.e, monoethanolamine has a greater irritating potential than diethanolamine, in accordance to the author's results. For the aliphatic and monoelectrolyte PILs it is evident that the increasing anionic chain decreases the irritant potential of the compound (2-HEAF > 2-HEAA > 2-HEAPr and 2-HEAL; 2-HDEAA > 2-HDEAL). The same behavior is observed for aromatic (2-HDEABe > 2-HDEASa) and polyelectrolytic PILs (2-HEAAd > 2-HEACi and 2-HDEAMa > 2-HDEAAd > 2HDEACi), which could be explained by the fact that complex structures with higher steric hindrance effect (high molar volumes) have greater resistance to passage across biological membranes, reducing its ocular irritating potential. Additionally, the recurring opacity effect observed in the gray scale graphs (although often not visually perceptible) may be due not necessarily to an irritating character of the PILs, but to the hypotonic nature of the samples (where the cell contains a higher concentration of solutes than the solution, and water moves into the cell causing swelling of the ophthalmic tissues), as previously observed for saline compounds [15].

\section{CONCLUSION}

The eye irritation potential of 13 protic ionic liquids was determined using a HET-CAM test and a modified quantification method. In order to represent the ophthalmic situation in vivo, the HET-CAM test uses the functional vasculature of the chicken's placenta and this acknowledged approach was analysed using a combination of two free software, ImageJ and Photoscape, as a modified 
quantification method to evaluate the amount of haemorrhaging, hyperemia and coagulation, producing a quantitative result to a previously qualitative test. The HET-CAM test is useful as a model for ophthalmic tissue since the chorioallantoic membrane is a complete tissue containing arteries, veins and capillaries that respond to inflammatory stimuli, and can be evaluated for results that are associated with ocular injuries, besides avoiding animal experimentation. Depending on concentration and structural features, the toxicity profile of ILs may vary, but by rational design, the irritating potential can be mitigated knowing a structure-toxicity relationship.In view of the need to perform the toxicity assessment to confirm fully green PIL behaviour, this modified method can be the key towards providing the predictive ability which could guide the design of novel greener ILs for industrial application.

\section{REFERENCES}

1 ÁlVAREZ, V.H., Iglesias, M., Dosil, N., Gonzalez-Cabaleiro, R., Martin-Pastor, M., Mattedi, S., Navaza, J. M. Brønsted ionic liquids for sustainable processes: synthesis and physical properties, J. Chem. Eng. Data, 55 (2010) 625-632. https://doi.org/10.1021/je900550v.

2 ADAWIYAH, N., Moniruzzaman, M., Hawatulaila, S., Goto, M. Ionic liquids as a potential tool for drug delivery systems, Med. Chem. Commun. 7 (2016) 1881-1897. https://doi.org/10.1039/C6MD00358C.

3 HIJO, A.A.C.T., Maximo, G.J., Costa, M.C., Batista, E.A.C., Meirelles, A.J.A. Applications of ionic liquids in the food and bioproducts industries, ACS Sustain. Chem. Eng. 4 (2016) 5347-5369, https://doi.org/10.1021/acssuschemeng.6b00560.

${ }^{4}$ ANDRADE, R.S., Torres, D., Ribeiro, F.R., Chiari-Andréo, B.G., Oshiro, J.A. Jr., Iglesias, M. Sustainable cotton dyeing in nonaqueous medium applying protic ionic liquids. ACS Sustain. Chem. Eng. 5 (2017) 8756-8765. https://doi.org/10.1021/acssuschemeng.7b01555.

${ }^{5}$ RANKE, J., Stolte, S., Störmann, R., Arning, J., Jastorff, B. Design of sustainable chemical products - the example of ionic liquids, Chem. Rev. 107 (2007) 21832206, https://doi.org/10.1021/cr050942s.

${ }^{6}$ KUMAR, R.A., Papaïconomou, N., Lee, J.M., Salminen, J., Clark, D.S., Prausnitz, J.M. In vitro cytotoxicities of ionic liquids: effect of cation rings, functional groups, and anions, Environ. Toxicol. 24 (2009) 388-395. https://doi.org/10.1002/tox.20443.

7 OLIVEIRA, M.V.S., Vidal, B.T., Melo, C.M., Miranda, R.C.M., Soares, C.M.F., Coutinho, J.A.P., Ventura, S.P.M., Mattedi, S., Lima, A. S. (Eco)toxicity and biodegradability of protic ionic liquids, Chemophere. 147 (2016) 460-466, https://doi.org/10.1016/j.chemosphere.2015.11.016.

${ }^{8}$ KAUSHIK, N.K., Attri, P., Kaushik, N., Choi, E. H. Synthesis and antiproliferative activity of ammonium and imidazolium ionic liquids against T98G brain cancer cells, Molecules. 17 (2012) 13727-13739. https://doi.org/10.3390/molecules171213727.

9 HWANG, J., Park, H., Choi, D.W., Nam, K.T., Lim, K.M. Investigation of dermal toxicity of ionic liquids in monolayer-cultured skin cells and 3D reconstructed human skin models, Toxicol. in vitro. 46 (2018) 194-202. https://doi.org/10.1016/j.tiv.2017.09.025. 
${ }^{10}$ PÉREZ, S.A., Montalbán, M.G., Carissimi, G., Licence, P., Víllora, G. In vitro cytotoxicity assessment of monocationic and dicationic pyridinium-based ionic liquids on HeLa, MCF-7, BGM and EA.hy926 cell lines,J. Hazard. Mater., (2019) 121513. https://doi.org/10.1016/j.jhazmat.2019.121513.

${ }^{11}$ ARUNKUMAR, R., Abraham, A.N., Shukla, R., Drummond, C.J., Greaves, T.L. Cytotoxicity of protic ionic liquids towards the HaCat cell line derived from human skin,J. Mol. Liquids.314 (2020) 113602. https://doi.org/10.1016/j.molliq.2020.113602.

${ }^{12}$ ENVIRONMENTAL PROTECTION AGENCY (EPA), Alternative Test Methods and Strategies to Reduce Vertebrate Animal Testing. https://www.epa.gov/assessingand-managing-chemicals-under-tsca/alternative-test-methods-and-strategies-reduce, 2018 (accessed 02 August 2020).

${ }^{13}$ EUROPEAN CHEMICAL AGENCY (ECHA), Advice on skin and eye irritation testing helps reduce animal tests, ECHA/NA/16/28. https://echa.europa.eu/-/adviceon-skin-and-eye-irritation-testing-helps-reduce-animal-tests, 2016 (accessed 02 August 2020).

${ }^{14}$ ORGANIZATION FOR ECONOMIC CO-OPERATION AND DEVELOPMENT (OECD) TG 263. OECD guidelines for the testing of chemicals test, no. 263: Guidance Document on an Integrated Approach on Testing and Assessment (IATA) for Serious Eye Damage and Eye irritation.

http://www.oecd.org/officialdocuments/publicdisplaydocumentpdf/?cote=ENV-JMMONO(2017)15/REV1\%20\&doclanguage=en, 2017 (accessed 02 August 2020).

15 MACKEnZIE, B., Kay, G., H. Matthews, K. H., Knott, R. M., Cairns, D., International Journal of Pharmaceutics, 490, 1-8, 2015. 